\title{
SALUD
}

\section{Empoderamiento de enfermería en las unidades de cuidados intensivos. Hospital Central del Instituto de Previsión Social}

\author{
Nancy Villagra Rivera', Mónica Ruoti²
}

\begin{abstract}
Resumen
Introducción: El empoderamiento es el proceso por el cual las personas fortalecen sus capacidades, su confianza, su visión y protagonismo para impulsar cambios positivos de las situaciones que viven, por ello es un desafío para los profesionales de enfermería en todos los niveles de asistencia. En las unidades de cuidados intensivos, la condición del enfermo crítico requiere vigilancia continua y quien dispensa este servicio es el enfermero/a asistencial. Pese a ser importantes en la evolución de los enfermos, los profesionales de enfermería muestran un perfil bajo en relación a otros miembros del equipo de salud. Sus acciones son silenciosas, carecen de evidencia y principalmente, muestran desorganización individual y colectiva. Las propuestas de Marc Zimmerman en materia de empoderamiento y Patricia Benner en lo relacionado el desarrollo profesional de enfermería constituyen el enfoque teórico desde donde se aborda la problemática
\end{abstract}

Objetivo: el objetivo de esta investigación es realizar un análisis del empoderamiento de los enfermeros/as asistenciales de cuidados intensivos de adultos en el Hospital Central del Instituto de Previsión Social en la ciudad de Asunción, Paraguay. Se realizó un estudio cualitativo con enfoque fenomenológico.

Material y Método: A partir de la revisión bibliográfica se identificaron cualidades que posee la persona empoderada las cuales constituyeron las siguientes 6 categorías de estudio: sentido de pertenencia, autonomía, liderazgo, trabajo en equipo, asociación a organizaciones y percepción de empoderamiento. La muestra se determinó por conveniencia y saturación alcanzando a 17 sujetos. Los datos se recolectaron a través de entrevistas semiestructuradas las que fueron almacenadas en una grabadora digital y se desarrollaron de manera flexible teniendo en cuenta la multiculturalidad de la población paraguaya, así como su bilingüismo. En forma confidencial se transcribió la totalidad de las entrevistas y luego, en una segunda etapa, fueron mostradas a los respectivos entrevistados/as para su aprobación.

1. Universidad Católica Nuestra Señora de la Asunción (UCA), Paraguay.

Tesis presentada al Programa de Magíster en Enfermería de la UCA.

2 Tutora de Tesis.

E-mail: enfernancy@hotmail.com

DOI: 10.26885/rcei.foro.2017.140 


\section{Empoderamiento de enfermería en las unidades de cuidados intensivos. Villagra y Ruoti}

Resultados: los resultados obtenidos muestran un grupo de profesionales jóvenes con predominio del sexo femenino y una permanencia entre 4 y 13 años en las unidades de cuidados intensivos.

La primera categoría estudiada muestra que el sentido de pertenencia hacia la profesión es una motivación incipiente entre los enfermeros/as que trabajan en las áreas críticas.

La autonomía es una práctica sistemática entre los profesionales de enfermería de esta área; éstos afirman que la mayor parte del tiempo deben tomar decisiones relacionadas con el cuidado del paciente y por el bien del paciente. Aseguran que se sienten capaces de tomar decisiones y que esta capacidad la adquieren gracias a la experiencia y el conocimiento adquiridos en la práctica clínica. Reconocen que la autonomía se refiere a la capacidad de tomar decisiones y es una práctica habitual que implica priorizar acciones de cuidado al enfermo.

La práctica del liderazgo en los enfermeros asistenciales estudiados se da de manera condicionada, ya que existen factores negativos que impiden su total ejercicio. Los/as enfermeros/as asistenciales, reconocen su rol de cuidador y revelan que la falta de insumos es la principal y más importante limitación para desempeñar sus funciones. La influencia positiva es relativa, ya que las sugerencias que dan a sus compañeros de trabajo dependen muchas veces del receptor. Un motivo importante para que los compañeros no tomen en cuenta las sugerencias, es el hecho de que las reglas no son claras y esto hace que el liderazgo sea difícil de practicar.

Los/as enfermeros/as asistenciales perciben que trabajan en equipo dentro de su guardia y que esta forma de trabajo es propia de las unidades de cuidados intensivos. Se identifican hechos puntuales de compañeros exigentes e incluso, discusiones entre los integrantes del grupo. Sin embargo, los participantes aseguran que las normativas del servicio y de la institución no están difundidas adecuadamente y si bien algunas normas son conocidas, no se respetan.

En relación a la participación en asociaciones, se identifica a la Asociación Paraguaya de Enfermería y los sindicatos de trabajadores dentro del Hospital Central. Los entrevistados manifiestan que se encuentran asociados pero, en general, la participación es pasiva y no se involucran activamente por motivos como falta de tiempo, desinterés y desconfianza, principalmente hacia los líderes de las organizaciones. Hay quienes manifiestan que ingresaron a los sindicatos en forma obligatoria y que estar asociados a ellos implica un gasto de dinero. Otra corriente de opiniones muestra que los/as enfermeros/as asistenciales se asocian a los sindicatos por la necesidad de conocer sus derechos y beneficios. Los participantes manifiestan escaso interés por participar en la Asociación Paraguaya de Enfermería; incluso hay quienes afirman que la siguen sólo por redes sociales.

Acerca de la percepción de empoderamiento, las respuestas son variadas y en algunos casos fue necesario definir el concepto. Hay quienes manifiestan 
categóricamente que sienten empoderamiento individual. Los entrevistados reconocen que la enfermería en Paraguay aún tiene una imagen profesional incipiente.

Se afirma que el empoderamiento existe cuando un enfermero es capaz de solucionar problemas durante su guardia sin supervisión y sin esperar que las autoridades reconozcan lo bueno de sus intervenciones. Otra idea recogida del discurso de los entrevistados muestra que los profesionales reconocen que al no haber integración, trabajo en equipo y solidaridad, no se da empoderamiento profesional.

Conclusiones: Si se consideran las apreciaciones recogidas, la percepción de empoderamiento genera sentimientos encontrados que permiten afirmar que no existe empoderamiento de la enfermería profesional en el nivel individual.

Palabras clave: empoderamiento, enfermero/a asistencial, cuidados intensivos.

\section{REFERENCIAS}

Benner, P. (2001). From novice to expert: excellence and power inclinical nursing practice. Commemorative. New Jersey: Prentice-Hall Inc.

Cadena, J. (2015). Análisis reflexivo del empoderamiento de la enfermería mexicana: mito o realidad. Medigraphic., 23(1), 42-46.

Zimmerman, M. (2000). Empowerment theory: phycological, organizational and community levels of analisys. New York: Handbook of community psycology. 